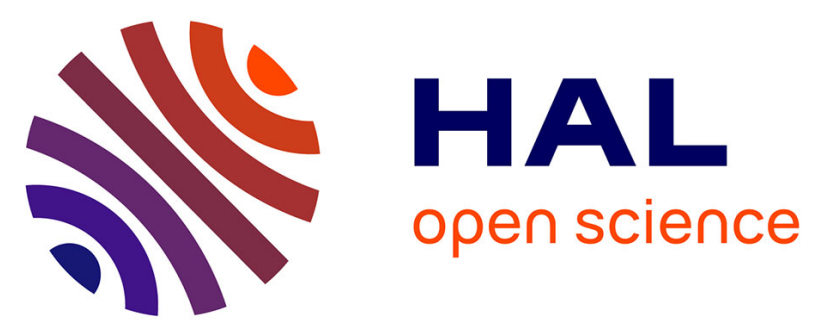

\title{
ADEL-maize: an L-system based model for the integration of growth processes from the organ to the canopy. Application to regulation of morphogenesis by light availability
}

Christian Fournier, Bruno Andrieu

\section{To cite this version:}

Christian Fournier, Bruno Andrieu. ADEL-maize: an L-system based model for the integration of growth processes from the organ to the canopy. Application to regulation of morphogenesis by light availability. Agronomie, 1999, 19 (3-4), pp.313-327. hal-00885933

\section{HAL Id: hal-00885933 https://hal.science/hal-00885933}

Submitted on 1 Jan 1999

HAL is a multi-disciplinary open access archive for the deposit and dissemination of scientific research documents, whether they are published or not. The documents may come from teaching and research institutions in France or abroad, or from public or private research centers.
L'archive ouverte pluridisciplinaire HAL, est destinée au dépôt et à la diffusion de documents scientifiques de niveau recherche, publiés ou non, émanant des établissements d'enseignement et de recherche français ou étrangers, des laboratoires publics ou privés. 


\title{
Original article
}

\section{ADEL-maize: an L-system based model for the integration of growth processes from the organ to the canopy. Application to regulation of morphogenesis by light availability}

\author{
Christian Fournier, Bruno Andrieu* \\ Unité de recherche en bioclimatologie, Inra, 78850 Thiverval-Grignon, France
}

(Received 10 November 1998; accepted 26 February 1999)

\begin{abstract}
ADEL-maize is a crop simulation model, whose specific feature is to consider the canopy as a set of individual plants. It combines a 3D model of maize development with physical models computing the microclimate on the 3D structure. Processes within the plant are described at the level of individual organs. We complemented the previous version of ADEL that simulated development as a function of temperature, with a module for the regulation of growth by dry matter availability. Dry matter production is based on the concept of light-use efficiency and allocation is a function of the sink strength of each organ, calculated according to organ size and temperature. Validation against independent data sets demonstrates the ability of the model to simulate the effects of density on leaf development and, to a lesser extent, on stem development. Finally, we present and discuss some simulations of the development of variability between plants. (C Inra/Elsevier, Paris.)
\end{abstract}

maize / individual based crop model / carbon allocation / morphogenesis / L-system

Résumé - ADEL-maïs : un modèle fondé sur l'approche L-système pour l'intégration organe - plante - peuplement. Application à la régulation de la morphogenèse par la ressource lumineuse. ADEL-maïs est un modèle de fonctionnement de culture dans lequel le couvert est considéré comme une population de plantes en interaction. Il couple un modèle 3D de développement du maïs avec des modèles de microclimat sur maquettes tridimensionnelles. Le fonctionnement de la plante est décrit à l'échelle de l'organe. La version précédente d'ADEL, simulant le développement en fonction de la température, est ici complétée par un module de gestion des régulations trophiques. La production de matière sèche est calculée pour chaque plante, en utilisant le concept d'efficience d'utilisation de la lumière. L'alloca-

Communicated by Gérard Guyot (Avignon, France)

* Correspondence and reprints

andrieu@bcgn.grignon.inra.fr 
tion considère les forces de puits de chaque organe, évaluées suivant leur taille et leur température. La comparaison avec des résultats indépendants démontre la capacité du modèle à simuler les effets de la densité sur le développement des feuilles et, dans une moindre mesure, sur le développement de la tige. Nous présentons et discutons quelques simulations montrant le développement de la variabilité entre plantes. (C Inra/Elsevier, Paris.)

maïs / modèle de population de plantes / allocation du carbone / morphogenèse / L-système

\section{Introduction}

Crop modelling requires combining physiological models of growth and development as a function of microclimate and resources capture, together with models simulating the evolution of the physical environment as a function of crop structure and the boundary conditions. In most approaches, these interactions are treated by idealising the canopy as a continuous, homogeneous or stratified, medium: plant characteristics are abstracted through averaged variables such as the leaf area density and the leaf orientation distribution, whereas microclimatic conditions are represented through averaged values or functions such as the vertical profiles of light and temperature. These models describe idealised homogeneous crops in which horizontal heterogeneity and plantto-plant variability is neglected. Heterogeneity is, however, often encountered in agronomic systems owing to the cultural practices (intercropping, mixture of varieties), variability of the date of emergence [45], or created by diseases or competition with weeds.

An alternative approach is to simulate the crop as a population of plants interacting for resource acquisition. This requires the development of plant - rather than canopy - growth models, and to calculate the microclimate at the level of individual plant organs. The L-system formalism (see Prusinkiewicz [48]) has been used extensively by computer-scientists as a language to perform visual simulations of plant growth. It codes plant development as the parallel functioning of plant sub-units (the modules) and enables production of dynamic three-dimensional (3D) outputs of plants. Sohbi and Andrieu (reported in [19]) implemented a bi- directional interface between the L-system software 'Graphtal' [54] and microclimate models. Mech and Prusinkiewicz [37] introduced the concept of open L-System, i.e. a general formalism for the exchange of information between L-system and external procedures. The recent generation of software for plant architectural modelling [26, 32, 49], now includes that feature, providing the ability to account for interactions between plants and their environment.

Until now, most of the growth models implemented using L-systems were designed for demonstration purposes, and used very simplified descriptions of the biophysical processes. Significant efforts have focused on the simulation of the growth of trees with a time step of 1 year (e.g. [42]). In contrast, attempts to use environmental architectural plant models for agronomic purposes are rare. Goel et al. [22] and DìazAmbrona et al. [10], working with maize and faba bean, respectively, implemented architectural models of development as a function of thermal time. However, in their approaches, the temperature was taken as input and microclimatic computations did not influence plant development. We [20] presented a 3D architectural and process-based model, named ADEL (architectural model of development based on L-systems), that simulates the development of maize as a function of temperature of organs. In ADEL-maize, the time step is variable, but typically of a few hours to 1 day, enabling a mechanistic description of both the physiological process and changes in the plant environment. The temperature of the growing zone, and thus growth rate, are calculated at each time step for each plant, according to climatic conditions and the $3 \mathrm{D}$ structure of the plants. In this paper, the model is com- 
plemented by taking into account dry matter availability. Dry matter production is calculated from the light intercepted by individual plants. A module for carbon allocation and rules for the regulation of morphogenesis by carbon availability are included. This enables simulation of interplant competition for light.

\section{Materials and methods}

\subsection{Model overview}

\section{ADEL-maize consists of four components (figure 1):}

1) a model for the growth and development of individual organs, based on temperature and carbon availability;

2) a model for production and allocation of dry matter; this model calculates carbon availability to individual organs;

3) organ shape models that enable a 3D representation of the plants;

4) environmental models that calculate the distribution of light and temperature at specific sites in the 3D structure of the plants.

The model for growth and development presently focuses on the aerial vegetative structures, without consideration of the reproductive organs. Three processes are involved: initiation of phytomers (i.e. one internode and the attached leaf) by the apex, growth of the leaves, and growth of the internodes. Potential growth in the absence of carbon restriction is based on i) the kinetics of leaf and internode elongation as a function of temperature, ii) a parameterisation of leaf width as a function of distance to leaf tip, and iii) a parameterisation of

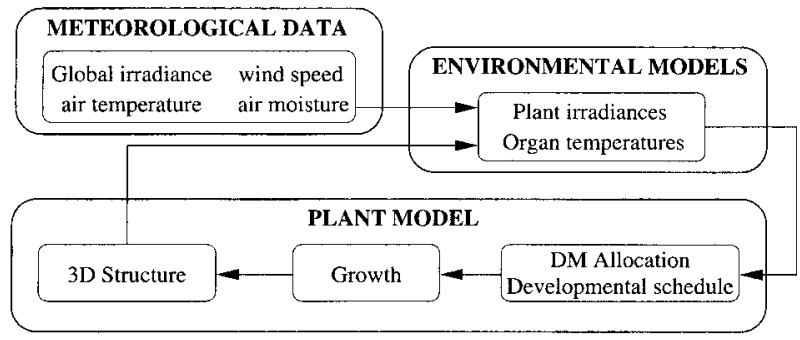

Figure 1. Flow diagram showing the relationships among submodels involved in ADEL. internode diameter as a function of internode rank. These parameterisations are adapted from Prévot et al. [47] for leaf width, and from our own measurements on the cultivar Déa for internode diameters.

The conceptual scheme for the interactions between responses to temperature and to carbon availability derives from that in CERES-maize [28]. At each time step, growth of organs is calculated as a function of temperature and converted to dry mass requirements based on a minimal value for specific leaf area and specific internode volume. These parameters are assumed to be constant, as they represent structural requirements, not including the lignification of organs or the storage of assimilates that occur after elongation. The structural needs are compared to the dry mass allocated to each organ and result in growth restriction if the allocated dry mass is less than the needs. Rules for carbon allocation between organs will be presented later. When total dry mass production exceeds the needs of all growing organs, dry mass is stored. Stored dry mass is not available for growth during the vegetative stage.

The 3D representation of the plants is performed through a process of geometric interpretation of parameters relative to the shape of the organs. The geometric interpretation uses standard facilities incorporated in 'Graphtal' [54], and requires a geometric parameterisation of each module. Internodes are represented by cylinders, with length and diameter calculated in the physiological model. Representation of the leaves is based on leaf lengths and widths calculated in the physiological model, plus a parameterisation of the midrib curvature after Prévot et al. [47] and a distribution of leaf azimuth derived from Drouet and Moulia [11]. Empirical distributions of parameters allow a reproduction of a variety of shapes. Parameterisations of laminae undulations occurring in maize leaves have been developed $[1,16]$; however, the authors showed that taking into account theses undulations did not significantly change the calculation of radiative transfer [17, 18]. Thus these parameterisations were not introduced here.

The interception of light by individual phytoelements and the temperature of the growing zone are calculated at each time step for each plant. Estimating dry matter production requires calculating the interception of photosynthetically active radiation (PAR), for which multiple scattering can be neglected. Direct light from the sun and the sky on each individual plant organ is calculated by projecting the 3D structure along a set of directions sampling the sky hemisphere. In maize all growing parts concentrate close to the apex. The temperature of this region of the plant is calculated using the energy balance model presented by Cellier et al. [5] and improved by Guilioni and Cellier (unpublished). 
The 3D representation of plants and the calculation of microclimate near the apex of the plant are documented in Fournier and Andrieu [20] and will not be further described here. Few changes were made to modelling plant developmental responses to temperature - a detailed description is also provided in Fournier and Andrieu [20]. Here we will briefly summarise the main features of modelling the developmental responses, and present the rules by which carbon is allocated and by which growth is restricted when carbon does not supply the needs.

\subsection{Responses to temperature}

\subsubsection{Scheme of development}

Plant development during the vegetative stage is captured as the repetition of an invariable developmental sequence involving three modules: the apex, the leaf (blade + sheath) and the internode. The apex initiates young phytomers, consisting of a leaf primordium and a primordium insertion disc. An individual leaf blade elongates first, followed by a leaf sheath at the end of blade growth, and by the internode at the end of sheath growth. We neglect the short overlaps that exist between the growth of the components of a phytomer. This sequence is supposed to be unaffected by the environment. The sequence stops with the initiation of the tassel by the apex. Elongation of internodes is considered inhibited before tassel initiation [36], which results in the most basal internodes remaining short. There are typically five or six short internodes for a plant with 16 leaves.

\subsubsection{Initiation of phytomers}

Four phytomers are already present in the seed embryo. The total number of vegetative phytomers is calculated according to the empirical model proposed by Grant [23]: the apex initiates, in a first stage, a genotype-dependant number of phytomers and then enters a transition stage. The duration of the transition stage is a genotype-dependant function of temperature and photoperiod. This duration determines the initiation of a variable number of additional vegetative phytomers.

The rate of initiation of phytomers by the apex is considered to depend on temperature alone. It is calculated with the function proposed by Warrington and Kanemasu [60], based on a study of two genotypes at 18 different temperature regimes.

\subsubsection{Leaf elongation}

The elongation of a grass leaf comprises three main stages: exponential growth during the establishment of the growing zone, linear growth and slowing down. Specific data for maize are reported in Thonat [58]. Since most of the elongation occurs during the period of linear growth, leaf elongation is here approximated by a broken line function with three parameters: the delay between the initiation of the primordium and the beginning of elongation, the growth rate and the growth duration.

The leaf elongation rate is considered to be independent of leaf rank. Its response to temperature is approximated as a linear increase between a base temperature Tbase and an optimal temperature Topt, then a linear decrease up to a maximal temperature Tmax. In our model, values for Topt $\left(31{ }^{\circ} \mathrm{C}\right)$ and Tbase $\left(9.8^{\circ} \mathrm{C}\right)$ are derived from Salah [51], and the choice of Tmax $\left(50{ }^{\circ} \mathrm{C}\right)$ is such as to approximate the response between 31 and $40{ }^{\circ} \mathrm{C}$, described in various studies $[25,52,63]$.

Blade and sheath growth durations, when expressed in degree-days (Tbase as above), are supposed to be independent of temperature. This results in a final leaf length independent of temperature for $\mathrm{T}<\mathrm{Topt}$, and a decrease in length for $\mathrm{T}>$ Topt. The durations (degreedays) are estimated as functions of the rank of the phytomer, with only two parameters, the total number of phytomers (calculated as explained above) and the growth duration for the blade and sheath of the longest leaf, considered as genotype-dependant parameters. The parameterisation by Dwyer and Stewart [12] of the variation of leaf area with leaf rank was the basis for our parameterisation of blade growth duration. We expressed the parameters of the model of Dwyer and Stewart as functions of the two parameters mentioned above, using data from various published data sets [8, $13,14,31,40,43,56]$ representing 22 genotypes. Figure 2 shows, on a representative subset of these data, that our parameterisation allows a reproduction of the individual leaf area of very different cultivars. By relating the individual leaf area to the total number of leaves only, Birch et al. [3] found excellent fits for five other genotypes.

The delay between leaf initiation and the beginning of leaf elongation has been calculated using a data set published by Cao et al. [4] and Zur et al. [65] on a single genotype.

\subsubsection{Internode elongation}

We found little information in the literature on the rate of elongation of internodes. In the previous version of ADEL, the internode elongation rate was estimated from published data sets to be equal to the leaf elongation rate multiplied by a constant coefficient 0.2 . Here we consider the coefficient to be 0.41 , according to results of recent experiments (Fournier, unpublished 


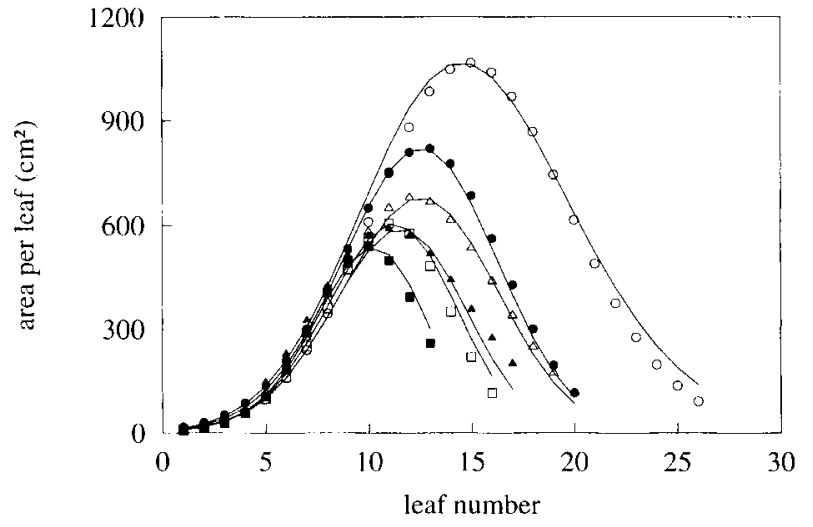

Figure 2. Area of leaf blade as a function of leaf rank for genotypes of maize with different numbers of leaves. Lines are for area calculated as a function of total number of leaves and area of the largest leaf. Symbols are for data by (a) Keating and Wafula [31], (A) Muchow Carberry [40], $(\triangle)$ Plénet [43], ( $\square$ and 0 ) Dwyer et al. [14], (O) Cooper [8].

data). Similarly to leaves, the durations of internode elongation are calculated from the growth rate and the final lengths. We built an empirical model for internode lengths as a function of leaf rank (figure 3), based on data by various authors $[15,27,39,50]$ and our own data for Déa. It uses two parameters: the length of the longest internode and the rank of the first internode that elongates. Taking into account the inhibition of stem elongation by the vegetative apex, this rank is taken as the rank of the oldest growing sheath at the date of tassel initiation. This typically leaves six short internodes for a genotype with 16 leaves, consistent with published data sets and our own observations.

\subsubsection{Visualisation of development}

The co-ordination of development between organs is summarised in figure 4 for a plant with 16 leaves. In our model, this scheme depends on genotype parameters alone and is insensitive to light availability. Three developmental events are reported to facilitate the comparison with results of simulations: tassel initiation, ear initiation and end of growth of the last blades. The date of ear initiation is not calculated in the model, but has been evaluated after Perthuis [41]. It results from the developmental sequence that elongation stops nearly simultaneously for the three last leaf blades; this is consistent with the observations by Thonat [58]. The figure also shows that the delay between leaf initiation and leaf elongation is large compared to the duration of leaf elongation.

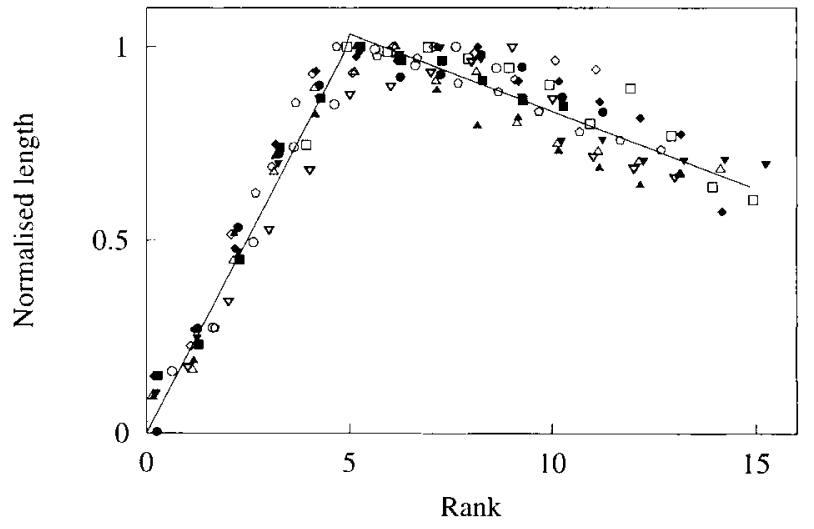

Figure 3. Normalised internode lengths as a function of the rank relative to the phytomer bearing the first elongated internode. Lengths are normalised to that of the longest internode. Data from: $(\square)$ Morrison et al. [39], $(\square, 0)$ Ephrath et al.

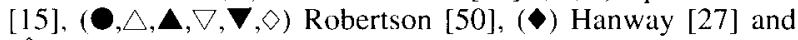
( $\square$ ) our own data on the DEA cultivar.

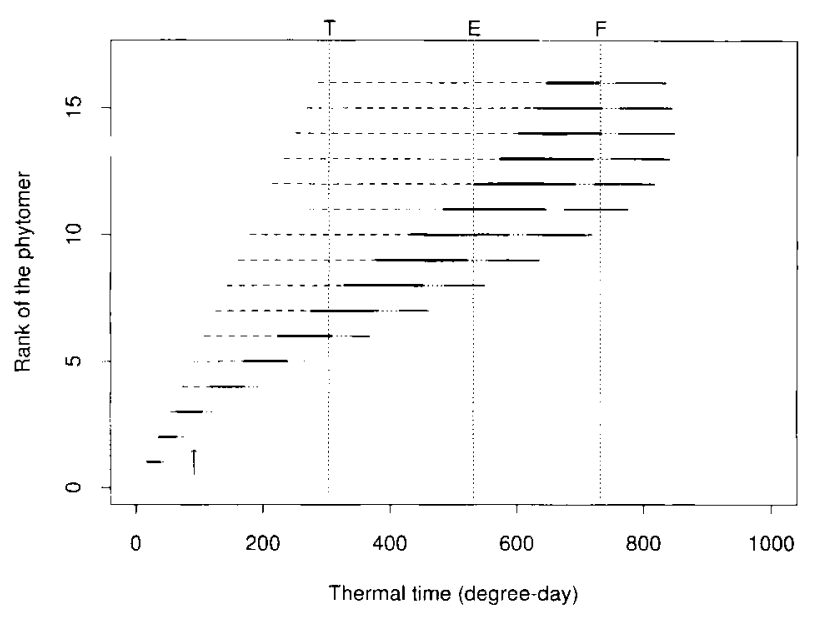

Figure 4. Coordinations of growth between phytomers on the main stem, simulated with ADEL for the Déa cultivar. Bars indicate periods of growth of the organs. Long dashed bars are for the period from leaf initiation to leaf elongation, bold bars for blade elongation, short dashed bars for sheath elongation and solid bars for internode elongation. Symbols correspond to the dates of the beginning of simulations (arrow), tassel initiation (T), ear initiation (E) and end of growth of the three last blades (F).

Developmental relationships and responses to temperature have been compared to various experimental data in a previous paper [20]. Evaluation of the model 


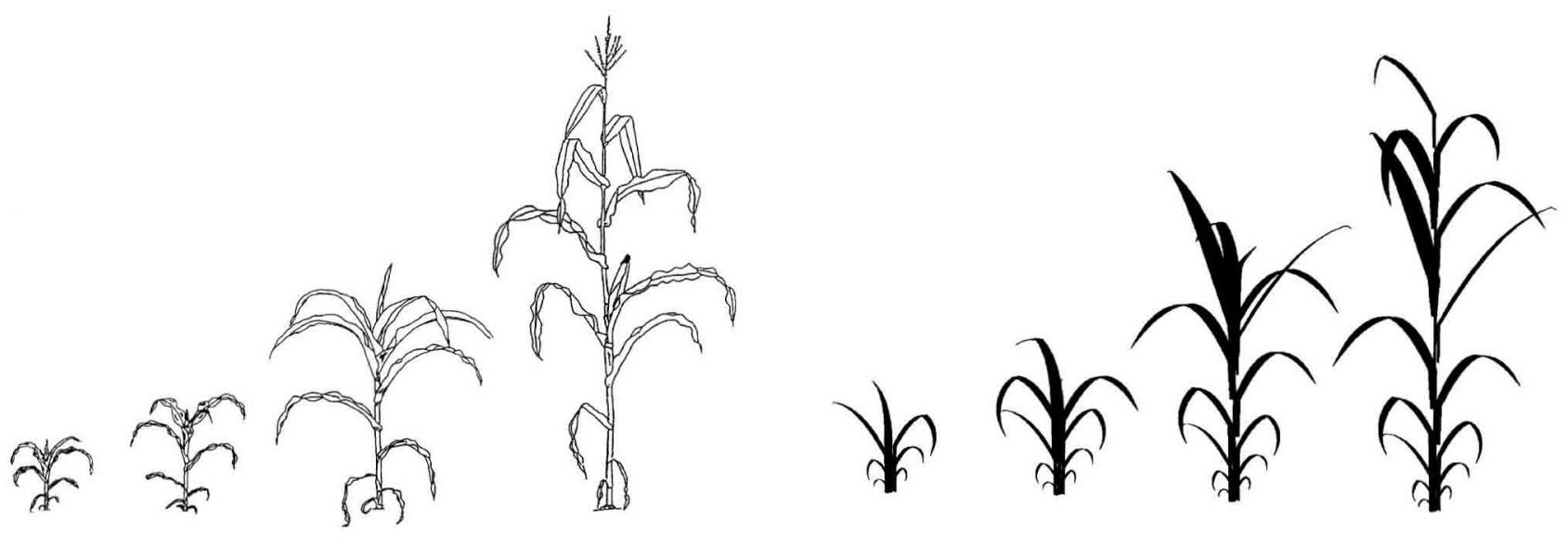

Figure 5. Hand-drawn and simulated plants of Déa cultivar at four stages of growth: 6, 8, 12 and 13 ligulated leaves on the main stem. Drawings are reprinted from Ledent et al. [33], with the authorisation of the editor (Service information du ministère de l'agriculture, Brussels).

was performed on several criteria such as leaf area development, vertical distribution of leaf area density, and relationships between leaf area index and ground cover. To illustrate the realism of the architectural model, the comparison between drawings of Déa plants at different stages by Ledent et al. [33] and plants simulated for the same stage is shown in figure 5. Figure 6 shows a simulated maize plot, with graphic rendering according to the distribution of PAR calculated in ADEL.

\subsection{Responses to light}

\subsubsection{Dry matter production}

We use, for individual plants, the approach proposed by Monteith [38] for a canopy. We calculate the dry mass increment for each individual plant as the product of the PAR intercepted by the plant and the light-use efficiency. The light-use efficiency is known to depend on the stage of development $[28,43]$; however, during the period from emergence to flowering, it is generally considered as a constant [28, 34]. Another simplification during this stage is to assume a constant proportion of assimilates being allocated to roots and shoot, and thus to consider an above-ground light-use efficiency $\varepsilon_{\mathrm{b}}$. These two simplifications seem valid for studying competition for light: the ratio between shoot and root biomass was found to be independent of density (ranging from 2.7 to 28.3 plants $\cdot \mathrm{m}^{-2}$ ) by Williams et al. [64], and

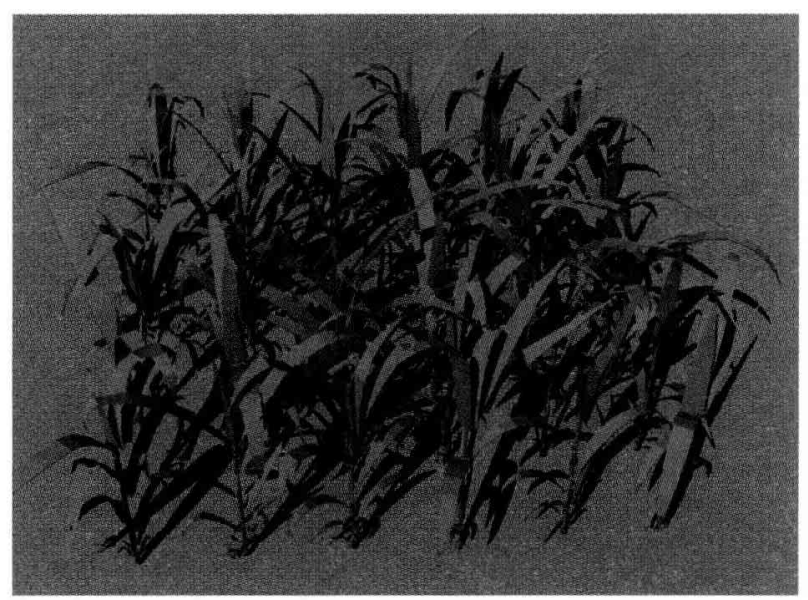

Figure 6. Visualisation of PAR distribution on a simulated 3D maize plot. The plot consists of 36 plants, at a density of 5 plants $\cdot \mathrm{m}^{-2}$. Incoming light is $40 \%$ from the sun and $60 \%$ diffuse.

$\varepsilon_{\mathrm{b}}$ was found to be constant for different densities by Giauffret et al. [21] and Popa [46].

We therefore calculate the daily dry mass increment for aerial structures $(\delta \mathrm{M}$, in $\mathrm{g})$ as:

$$
\delta M=\varepsilon_{r} \cdot \varepsilon_{b} \cdot R_{g}
$$

where $R_{y}$ is the daily total solar irradiance (MJ) intercepted by one plant, $\varepsilon_{\mathrm{r}}$ is the fraction of total solar irra- 
diance that is PAR $\left(\varepsilon_{\mathrm{r}}=0.48[59]\right)$, and $\varepsilon_{\mathrm{b}}=3.5 \mathrm{~g} \cdot \mathrm{MJ}^{-1}$ [34]. Note that $R_{g}$ is calculated from the $3 D$ output of the model, taking into account shading by other plants.

\subsubsection{Dry matter allocation}

When dry matter production exceeds total structural needs, allocation follows organ demands, and the supplement is stored. In the present version of ADEL, the stored dry matter is not distributed between organs, but is pooled at the plant level.

When total needs exceed the dry matter production, dry matter is distributed proportionally to the needs, that is:

$$
\delta A_{i}=\frac{\delta S_{i}}{\sum_{i} \delta S_{i}} \cdot \delta M
$$

where $\delta \mathrm{A}_{\mathrm{i}}$ is the dry mass increment allocated to organ $\mathrm{i}$, and $\delta \mathrm{S}_{\mathrm{i}}$ the structural needs of this organ.

Needs are calculated from potential increments of leaf surfaces and internode volumes using two parameters: the structural specific leaf area $\left(\rho_{\mathrm{s}}\right)$ and the structural specific internode volume $\left(\rho_{\mathrm{v}}\right)$. We measured the specific leaf area and specific internode volume of the growing parts of leaves (inside the whorl) and of growing internodes, in the case of plants grown under shade nets intercepting $80 \%$ of daylight (Fournier, unpublished data). We assumed that in these conditions, dry mass corresponded to purely structural material, and the values measured $\left(\rho_{\mathrm{s}}=36.1 \mathrm{~g} \cdot \mathrm{m}^{-2}, \rho_{\mathrm{v}}=15500 \mathrm{~g} \cdot \mathrm{m}^{-3}\right)$ were used to estimate structural needs in all simulations.

\subsubsection{Regulation of growth}

Rules for regulation of growth are based on published observations of the effects of plant density in maize. These effects could result from early detection of other plants through the phytochrome response to the $\mathrm{red} / \mathrm{far}$ red ratio [2] and by limitation of growth due to the progressive decrease of available light for individual plants. When the density increases from 0.8 plant $\cdot \mathrm{m}^{-2}$ to about 5 plants $\cdot \mathrm{m}^{-2}$, the effects are the reduction and suppression of tillering [55], an increase in internode and in leaf length $[24,30,55]$ together with a decrease in leaf width and internode diameter [30]. When the density increases from 5 to about 10 plants $\cdot \mathrm{m}^{-2}$, effects compare with a basipetal wave of stabilisation of leaf and internode lengths, and only the ten (for density of 5 plants. $\mathrm{m}^{-2}$ ) to six (density of 10 plants. $\mathrm{m}^{-2}$ ) lower phytomers still show an increase in organ length $[30$, 46]. Together with the stabilisation of lengths, there is a basipetal pattern of amplification of the decrease in leaf width an internode diameter [46]. For densities between 10 and 25 plants $\cdot \mathrm{m}^{-2}$, the width of leaves decreases further, and reduction in length occurs for the upper leaves [46]. However, leaf growth durations were found to be constant by Popa [46], suggesting that leaf elongation rate is reduced at high densities.

We believe that the suppression of tillering and the increase in leaf and internode lengths reported at low densities or for the basal phytomers, result primarily from the perception of the red/far red ratio by the phytochrome. These effects are not considered here, as we focus on the regulation of organogenesis by dry matter availability. Obviously, this restricts the domain of validity of our model to population density above 5 plants $\cdot \mathrm{m}^{-2}$, where tillering is mostly or totally inhibited. For density higher than $5-10$ plants $\cdot \mathrm{m}^{-2}$ (i.e. usual agronomic conditions), regulation by dry matter availability dominates, and leaf width and stem diameter are the first variables to be affected. We approximate the effects on leaf width by the narrowing of a predefined leaf shape [47], characterised by its maximal width $\mathrm{W}_{\mathrm{m}}$, the value of which is recalculated at each time step. Maximal width is, however, forbidden to decrease below the width of the fragment of leaf grown at the preceding step. Similarly, the internode diameter is reevaluated at each time step. According to the experimental results of Popa [46], we considered that the reduction in maximal leaf width and internode diameter are limited, respectively, to 60 and $75 \%$ of unstressed values. If, due to these limitations, the previous rules cannot accommodate the dry matter allocated to an organ, the rate of elongation of that organ is reduced for the current step. Since elongation duration remains constant, this results in a reduction of the final length of the organ.

\subsection{Simulations}

\subsubsection{Overview}

Two series of simulations are presented. The first series of simulations compares growth patterns corresponding to three densities $\left(5,15\right.$ and 25 plants $\cdot \mathrm{m}^{-2}$ ). Results are evaluated against published data sets corresponding to similar, although not identical, environmental conditions. Three types of results will be successively presented.

i) The dynamics of light interception by individual plants, to illustrate carbon availability corresponding to each treatment.

ii) The dynamics of the structural dry matter allocated to leaves. This allows a comparison of the period of 
carbon-limiting morphogenesis between the different treatments. The results for the simulation at a density of 5 plants $\cdot \mathrm{m}^{-2}$ are compared to an empirical function established by Maas [34] for maize grown at a density of 7 plants $\cdot \mathrm{m}^{-2}$. The parameters of this function were adjusted so that the function fitted the time course of leaf area development measured in a field experiment $[35]$.

iii) Finally, internode lengths and leaf areas, which are the main determinant for light interception, are compared to measurements by Popa [46] for the three densities.

The second series consists of simulations for a density of 25 plants $\cdot \mathrm{m}^{-2}$ with heterogeneity in the population. Heterogeneity is created by considering a few plants emerging 5 days sooner or later than the majority of the population. We present the time course of dry mass accumulation, chosen as a synthetic variable for the analysis of the variability in these systems.

\subsubsection{Parameterisation and environmental conditions}

Genotype parameters are those given by Fournier and Andrieu [20] for the Déa cultivar, and were estimated from plants grown in the field, at a density of 8 plants. $\mathrm{m}^{-2}$. The total number of leaves is 16 . Leaf and internode elongation durations are those given in figure 4. This corresponds to a potential length for the longest leaf and internode being 90 and $23 \mathrm{~cm}$, respectively.

To simplify the analysis of the results, environmental conditions were kept constant for all simulations. The temperature was $25^{\circ} \mathrm{C}$, the day length was $12 \mathrm{~h}$, during which the total irradiance was constantly $350 \mathrm{~W} \cdot \mathrm{m}^{-2}$. A diffuse radiation regime was simulated using 17 light sources positioned at the centre of a regular isosurfacic discretization of the sky hemisphere. A constant time step of 15 degree-days ( $24 \mathrm{~h}$ ) was used. To obtain continuous functions, the simulated dynamics of light interception and dry mass allocation have been smoothed using a quadratic local regression model [7].

The development of the embryo is not described in the model. Simulations begin with the initiation of leaf five and stop when stem elongation is complete, that is 750 degree-days (50 days) later. A population consists of 36 plants disposed on a $6 \times 6$ square (figure 6 ). Distances between rows and between plants within a row are equal and depend on density. To avoid border effects, only the four plants at the centre of the plot were taken into account to calculate the results. For the simulation of density effects, the results presented are the mean values for these four plants. For the simulation of heterogeneity, two of these four plants were out of phase in development, i.e. 5 days younger or older that the rest of the plot. In this case, results are presented individually for the four central plants.

\section{Results}

\subsection{Simulations at different densities}

\subsubsection{Light interception}

The three levels of density resulted in contrasting dynamics of light availability for individual plants (figure 7). At the lowest density, radiation interception increased with increasing leaf area throughout the period of simulation. Thus, each new leaf element contributed to an augmentation of the dry matter production. For the two other densities, intercepted PAR rapidly reached an asymptote, creating a constant regime for resource acquisition, independently of further development of the aerial structures. The asymptote was reached at ear initiation for the density of 25 plants $\cdot \mathrm{m}^{-2}$, and 6 days after ear initiation for the density of 15 plants $\cdot \mathrm{m}^{-2}$.

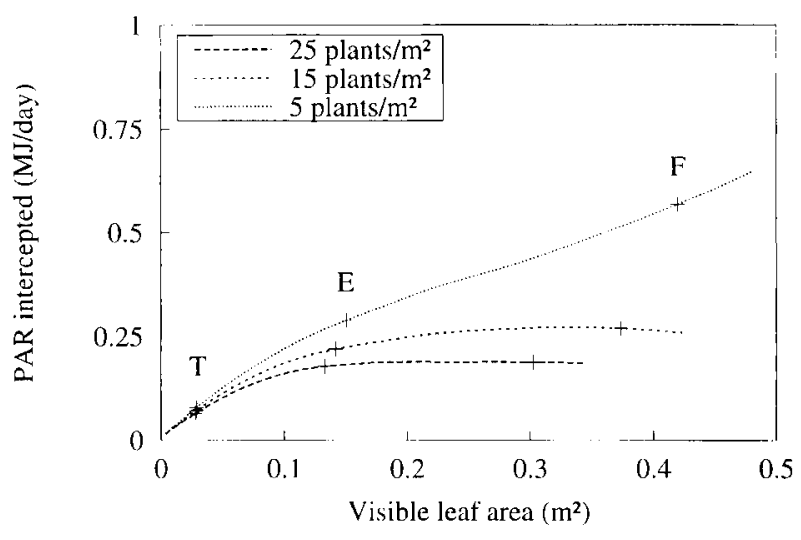

Figure 7. Simulations, for three densities, of the PAR intercepted per plants as a function of visible plant leaf area (mean values on the four central plants). Incoming PAR is $7.5 \mathrm{MJ} \cdot \mathrm{m}^{-2} \cdot \mathrm{day}^{-1}$. Crosses indicate successive tassel initiation, ear initiation and the end of growth of the last blade. Visible plant area increases after the end of blade growth, since sheath growth is required for a leaf to be totally visible. 


\subsubsection{Fraction of dry matter allocated to the leaves}

Despite the contrasting growth patterns created by the plant density treatments, the fraction of structural dry matter (total needs) allocated to the leaves during crop life was independent of density (figure 8). This illustrates that the stable developmental pattern (figure 4), together with the rules for dry matter management, results in the ratio between leaf area and stem volume being independent of plant density. This property is consistent with experimental data produced by Popa [46] and Kasperbauer and Karlen [30] for densities between 1 and 25 plants $\cdot \mathrm{m}^{-2}$ (figure 9). During most of the period where the stem and leaves grow together (from tassel initiation to end of growth of the last blade), structural needs of leaves represent almost $80 \%$ of the total needs. The curve presents a local maximum shortly after ear initiation, corresponding to the maximal rate of expansion of plant leaf area.

The fraction of total dry matter that corresponds to the structural needs of the leaves, is significantly affected by the density. As expected, the simulated density treatments behave identically at emergence, and differences between treatments increase with crop development (figure 8). The ratio between the two fractions (allocation of total dry matter divided by allocation of structural dry matter) represents the fraction of total dry matter that is structural dry matter. The higher the density, the higher this fraction and thus the less the storage. The period of storage closely matches the period where intercepted PAR increases with increasing leaf area (figure 7): storage occurs throughout the growth for the lowest density, before ear initiation for the highest density and until 6 days after ear initiation for the intermediate density. The regulation of growth, occurring with the disappearance of storage, lasted until the end of growth of leaves. The function adjusted by Maas [34] for a density of 7 plants. $\mathrm{m}^{-2}$, compares well with the simulation at density of 5 plants $\cdot \mathrm{m}^{-2}$ (figure 8 ).

\subsubsection{Dimensions of organs}

Experimental results by Popa [46] show decreased individual leaf areas as density increas-

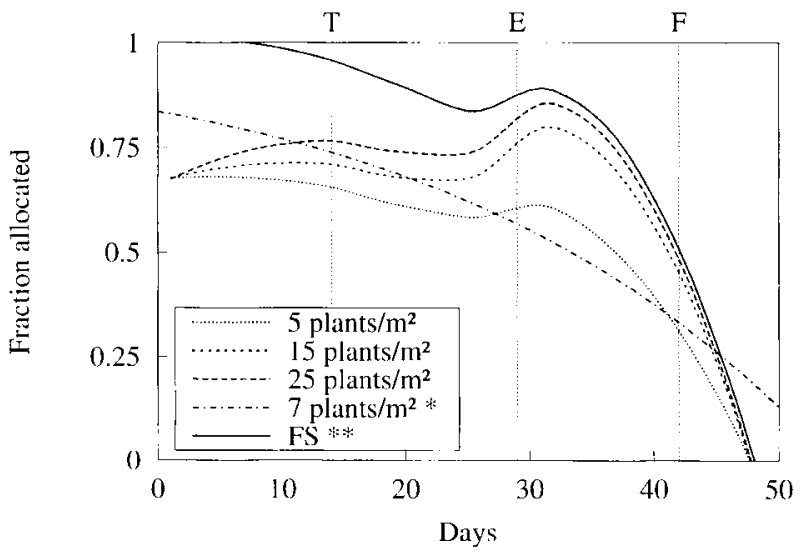

Figure 8. Temporal patterns of the allocation of structural dry matter to leaves for different densities. All curves are simulated with ADEL, except (*) which was established by Mass [34] against experimental data. Fractions are relative to total dry matter, except $(* *)$ which is the fraction relative to the total structural dry matter alone, and is identical for the three densities. Vertical lines indicate the date of tassel initiation, ear initiation and the end of growth of the last blade.

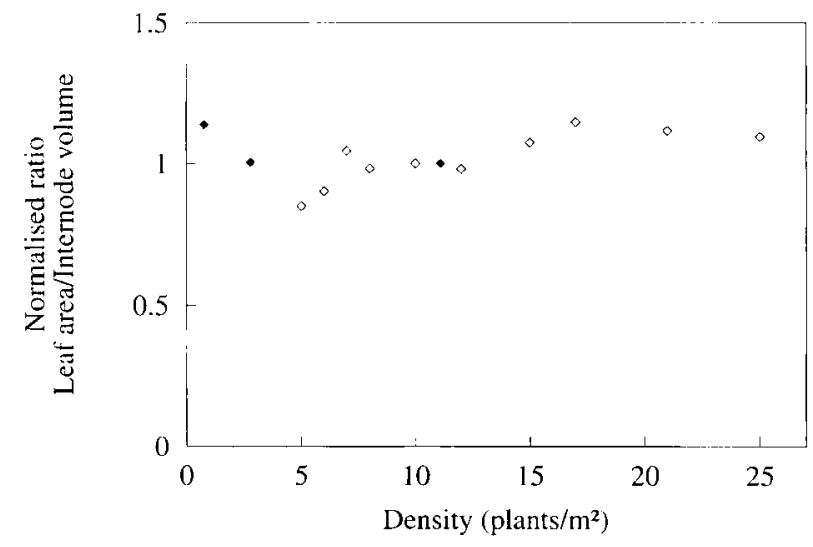

Figure 9. Normalised ratio between total leaf area and total internode volume for different densities. Ratios are normalised to the their value for a density of 10 plants $\cdot \mathrm{m}^{-2}$. Ratios are calculated from data by Popa [46] $(\diamond)$ and Kasperbauer and Karlen [30] $\bullet$ ).

es, the extent of which depends on leaf rank (figure 10a): leaves 1-7 are weakly affected, leaves 8-13 present increasing differences with leaf rank and leaves 14-16 moderately decreasing differences. These patterns are quite well reproduced with ADEL (figure 10a), despite a systematic 

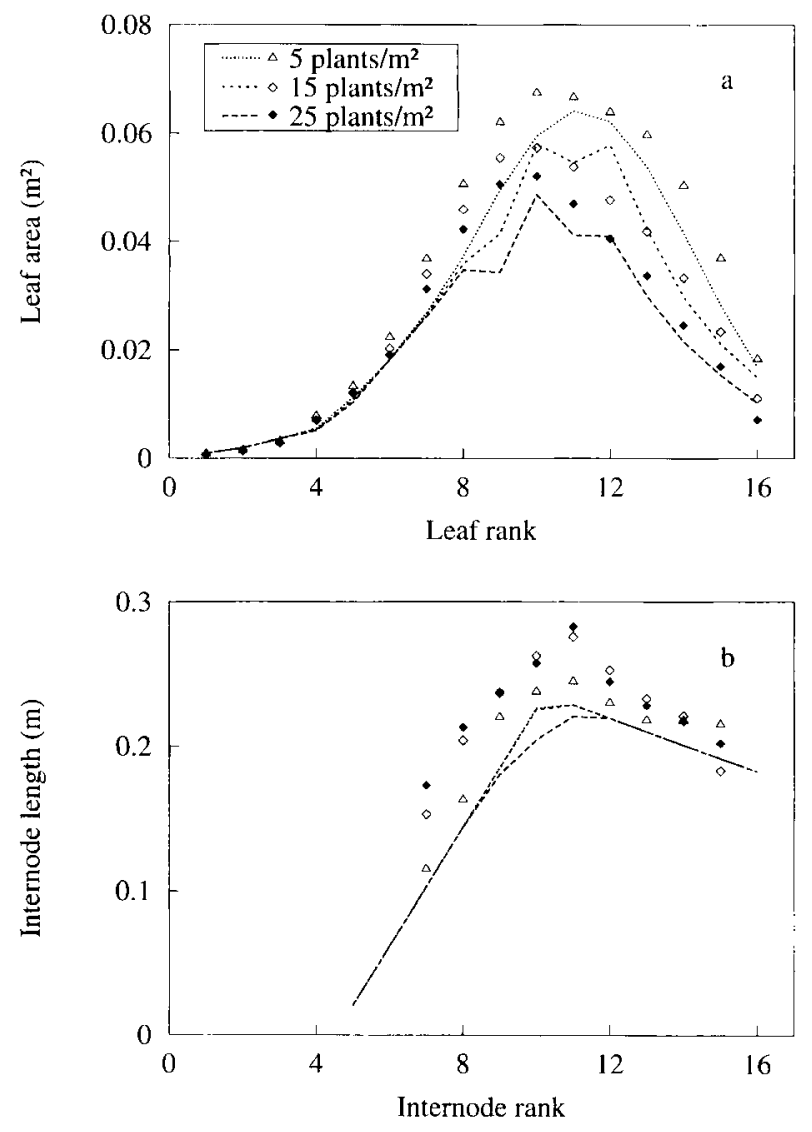

Figure 10. Leaf areas (a) and internode lengths (b) as a function of phytomer rank for three plant densities. Symbols are for experimental data by Popa. Lines are for simulations with ADEL.

underestimate of the area of leaves, especially for phytomers 7-11. These differences are probably due to an underestimation of the potential (i.e. corresponding to carbon non-limiting morphogenesis) value of leaf width, $W_{m}$, being carried into the estimates of leaf areas for higher densities by the application of the rules in the model. Another difference between simulations and measurements can be seen in figure 10a: at any density, measurements show a regular variation of leaf area with leaf rank, whereas simulations present some irregular patterns for the phytomers bearing the largest leaves. This could be due to the broken-line function that we used to describe leaf elongation. Taking into account the phase of exponential growth and of slowing down of leaf elongation would allow us to mimic more closely the evolution of the sink strength of the growing leaves.

The effect of density on individual internode lengths was underestimated with ADEL (figure $10 \mathrm{~b}$ ). The simulations at any density are close to the measurements made for the lowest density. In contrast, experimental results show that internodes $7-12$ are significantly longer at densities of 15 and 25 plants $\cdot \mathrm{m}^{-2}$ than at 5 plants $\cdot \mathrm{m}^{-2}$. As discussed above, we believe that this results from the response of the plants to light quality, which is not considered in this paper. The parameter we used for calculating maximal internode lengths originates from an experiment at a density of 8 plants. $\mathrm{m}^{-2}$; this explains the similarity with values of Popa at the lowest density. It is interesting to note, however, that the simulations reproduce the stability of lengths at high densities. This property illustrates the efficiency of reducing the internode diameter for reducing the needs and thus avoiding a reduction of length.

\subsection{Simulation with heterogeneity at emergence}

Variability developed even in the case of synchronous emergence. At the end of the simulation period, the ratio $s_{r}$ between the standard deviation and the mean value of individual plant dry matter, calculated for the four central plants, was $6.6,13.4$ and $18.6 \%$ for densities of 5,15 and 25 plants. $\mathrm{m}^{-2}$, respectively. Since only four plants were taken into account, $s_{r}$ is estimated here with a poor accuracy. However, the increase in variability with increasing plant density is consistent with experimental studies $[2,9]$. The time course of dry matter accumulation for individual plants in the high density plot is shown in figure lla. Heterogeneity remained low as long as intercepted PAR was proportional to leaf area (that is before ear initiation), then developed rapidly. At the end the four plants could be separated into two dominant and two dominated plants $(-25 \%$ of dry matter and $-27 \%$ of total area).

The four central plants were then separated into two groups, each group consisting of one dominant 

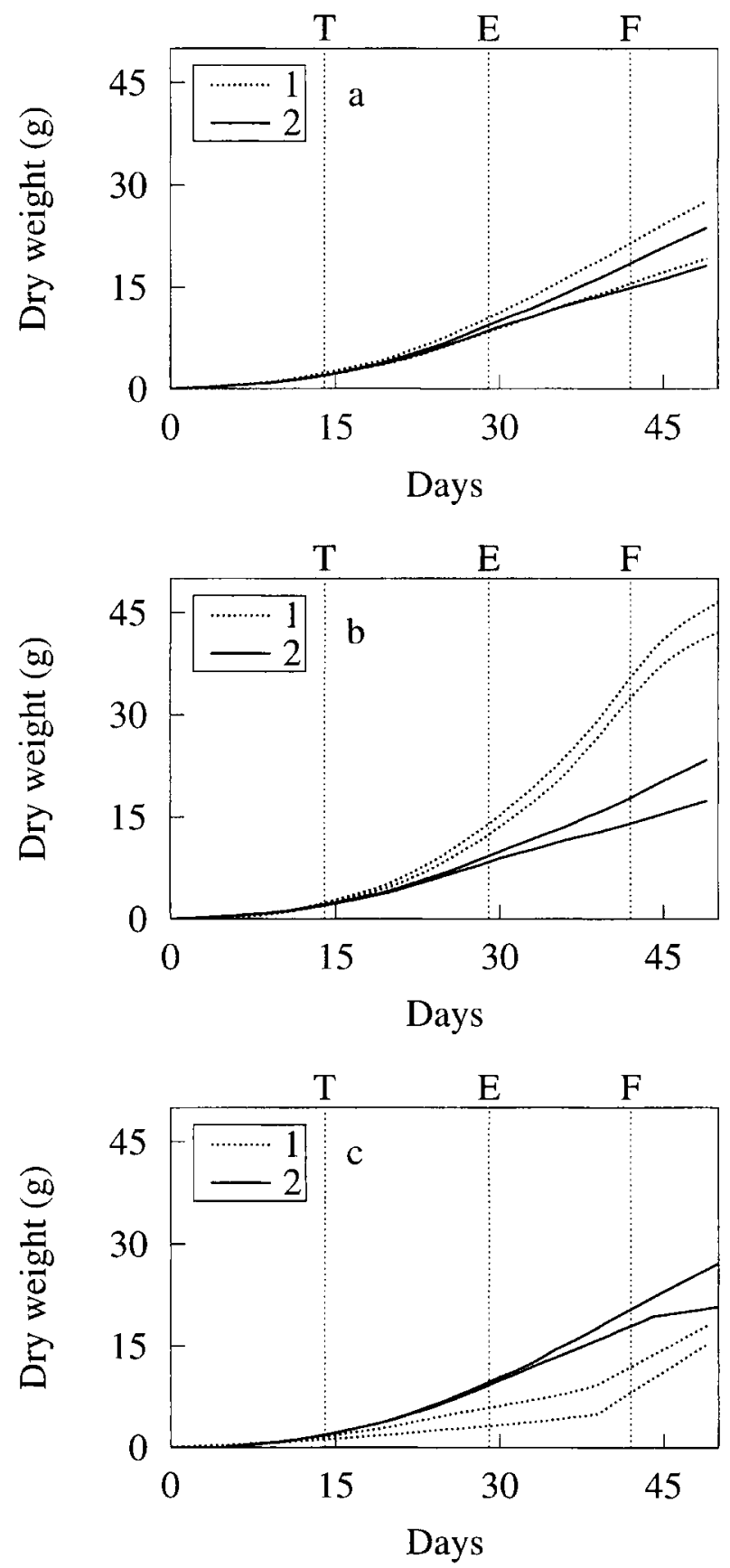

Figure 11. Simulation of the time course of the accumulation of dry matter for four individual plants, at a density of 25 plants $\cdot \mathrm{m}^{-2}$. The four plants are the central ones of a canopy of 36 plants and were separated into groups 1 and 2 (see text). (a) Simulation of an initially homogeneous canopy, (b) simulation with plants of group 1 being 5 days older than the rest of the canopy, and (c) simulation with plants of group $I$ being 5 days younger than the rest of the canopy. Vertical lines as in figure 7 . plant and one dominated plant from the previous simulation. Then simulations were performed with group 1 delayed in phase compared to the rest of the plot. The difference of 5 days used to introduce initial heterogeneity represented a difference of $55 \mathrm{~cm}^{2}$ of plant leaf area at the beginning of the simulations, and a difference of 5 days of the date of stem elongation.

Early emergence of two plants considerably changed their growth (figure $11 \mathrm{~b}$ ). At the end of the simulation, the leaf area of the previously dominant and dominated plants were +20 and $+60 \%$ higher than in the case of homogeneous initial conditions, respectively. The effect on dry matter accumulated was even more important $(+66$ and $+105 \%$ ). The two other central plants were only weakly affected: the leaf areas were 5 and $7 \%$ lower, and the accumulated dry matter was 2 and $3 \%$ lower, compared to the values in the first simulation. In the opposite situation, where the two plants emerged 5 days later than the rest of the plot, the effects were important for all four plants (figure 11c). The delayed plants presented final leaf areas 50 and $66 \%$ lower than in the case of homogeneous initial conditions, and accumulated dry matter was 33 and $21 \%$ lower. The other plants gained leaf area $(+15$ and $+20 \%)$ and accumulated more dry matter $(+11$ and $+13 \%)$.

\section{Discussion}

In our approach, the dependence on density of the function relating leaf area with leaf rank reflects the dynamic interaction that takes place between the interception of light, the co-ordination of growth between phytomers and the allocation processes. In our simulations, the regulations occurred during the period of constant light interception and, owing to the simple allocation rule we used (equation (2)), affect equally in intensity all simultaneously growing phytomers. During the period of stationary regime for light acquisition, the response to density for any given phytomer was simply related to the sink demand by others phytomers growing simultaneously. The good match 
between measured and simulated leaf area indicates that this scheme is relevant and stresses the importance of the scheme of co-ordination between organs to understand how phytomers are differentially affected by plant density.

Simple simulations presented in this study indicate that competition for light creates and amplifies heterogeneity. Even for an initially homogeneous canopy, heterogeneity appears. However, our results probably give an idea of extreme values, and overestimate the variability that actually occurs within a maize population. Pommel and Bonhomme [44], at a density of 13 plants $\cdot \mathrm{m}^{-2}$, found an increase of only $10 \%$ of leaf area when one plant had its four proximal neighbours removed at emergence. The larger variability observed in our simulations (figure $11 \mathrm{~b}, \mathrm{c}$ ) results partly from considering a higher plant density, but it probably also reflects the absence of compensatory effects in the rules of regulation in the model. The perception of neighbouring plants through the phytochrome and cryptochrome results in growth regulations that reduce the differences between dominated and dominant plants [2]. The distribution of the red/far red ratio on plant organs could be calculated by using the model of radiation distribution developed by Chelle and Andrieu [6] that takes into account multiple scattering; however, the photomorphogenetic regulation of dry matter allocation and organ elongation rates are only partly understood.

The simple scheme of allocation that we used seems quite appropriate for taking into account the effect of plant density on carbon availability. This may not be the case for any range of conditions resulting in carbon-limiting morphogenesis, especially those that imply sharp variation in the carbon budget (e.g. defoliation). The present approach neglects at least two aspects that should probably deserve attention for such applications.

- The first point deals with the description of sinks-source relations in the plant. Sinks have unequal access to sources, and sources produce different amounts of assimilates. Watson and Casper [62] and Watson [61] compiled data on a wide range of plants, including maize, and found evi- dences for organisation of the allocation at the level of plant sub-units. The heterogeneity of production among leaves is obvious: area exposed varies with leaf rank, light is attenuated with depth within the canopy and the efficiency of photosynthesis decreases with leaf age in maize $[13,53,57]$. The L-system formalism would allow us to take into account in ADEL simple rules for translocation of assimilates based on the position and strength of sinks and sources (e.g. [29]).

- The second point deals with the irreversibility of the growth processes. This results in constraints related to the history of development of organs that are not fully taken into account in the present version of ADEL. In our simulations, the width of a mature part of a growing leaf can vary at each time step owing to the regulation by scaling of the global leaf parameter, $W_{m}$ Similarly, the regulation of internode diameters results in either enlargement or shrinkage at each time step during internode growth. This allows for an integration over several time steps for the determination of maximal leaf widths and of internode diameters, but obviously violates the constraints brought by the irreversibility of the growth process. The thickening of leaves may also lead to an irreversible evolution of the structural specific leaf area. Whereas data by Popa [46] show that density effects on leaf shape can satisfactorily be approached by the scaling of a predefined leaf shape, we have experimental evidence that this is not true in the case of a sharp transition of the carbon budget, such as obtained when a shade net is installed or removed. The development of a mechanistic model for the acquisition of leaf shape, would require a study of the time scales to which leaf width adapts to the available carbon.

\section{Conclusion}

A simple model for dry matter management, requiring only three parameters, provided encouraging results in the simulation of the effects of plant density. The parameters are accessible to direct measurements and were taken from indepen- 
dent studies. We believe that this represents an interesting result owing, to a large extent, to the use of a modular description of the plant and of a $3 \mathrm{D}$ representation that allows an accurate calculation of the light intercepted by individual plants. Such a detailed approach also proved useful for understanding and illustrating the interactions between the processes involved, thanks to its capacity to generate data that are not or hardly measurable. For example, the model showed a cooccurrence between the establishment of a stationary regime for light interception and the beginning of the regulations of leaf morphogenesis by dry matter availability.

Plant-to-plant variability appeared systematically in our simulations, and we believe that it is a characteristic of the competition for light. This encourages the use of individual-based models for studying heterogeneous systems (crop/weed interactions, intercropping), and for a better understanding of the development of heterogeneity appearing in initially homogeneous canopies, and its consequences for crop production. Another interesting perspective is to provide parameterisations of functions required for simpler models (efficiency of light interception, allocation to organs). These functions are often difficult to define and, as demonstrated here, they vary with crop condition.

We believe that ADEL already provides an efficient framework for the integration from organ to canopy level. This study showed, however, that taking into account photomorphogenic processes would represent a significant improvement. The importance of the co-ordination scheme between individual organs also merits research into a better understanding of the processes responsible for that co-ordination.

Acknowledgements: Many thanks to $M$. Chelle for his help in the compilation of codes and for making us available his computer utilities for manipulating $3 \mathrm{D}$ virtual canopies. We express our gratitude to G. Popa for use of some of her unpublished results. A part this work was carried out at the Unité agropédoclimatique, Inra Guadeloupe, which is greatly acknowledged for supporting this work. Many thanks to $\mathrm{C}$. Birch for his useful review of the manuscript.

\section{References}

[1] Aries F., Modélisation surfacique de la structure d'un couvert végétal pour l'étude du rayonnement, thèse de doctorat, université de Nantes, France, 1997.

[2] Ballaré C.L., Scopel A.L., Sanchez R.A., Plant photomorphogenesis in canopies, crop growth, and yield, Hortscience 30 (1995) 1172-1180.

[3] Birch C.J., Hammer G.L., Rickert K.G., Improved methods for predicting individual leaf area and leaf senescence in maize (Zea mays), Aust. J. Agric. Res. 49 (1998) 249-262.

[4] Cao J., Hesketh J.D., Zur B., Reid J.F., Leaf area development in maize and soybean plants, Biotronics 17 (1988) 9-15.

[5] Cellier P., Ruget F., Chartier M., Bonhomme R., Estimating the temperature of a maize apex during early growth stages, Agric. For. Meteorol. 63 (1993) 35-54.

[6] Chelle M., Andrieu B., The nested radiosity model for the distribution of light within plant canopies, Ecol. Model. 111 (1998) 75-91.

[7] Cleveland W.S., Grosse E., Shyu W.M., Local regression models, in: Chambers J.M., Hastie T.J. (Eds.), Statistical Models in S, Wadsworth \& Brooks/Cole, Pacific Grove, Ca, USA, 1992, pp. 309-376.

[8] Cooper P.J.M., The association between altitude, environmental variables, maize growth and yields in Kenya, J. agric. Sci. 93 (1979) 635-649.

[9] Daynard T.B., Muldoon J.F., Plant-to-plant variability of maize grown at different densities, Can. J. Plant Sci. 63 ( 1983 ) 45-59.

[10] Díaz-Ambrona C.H., Tarquis A.M., Mínguez M.I., Faba bean canopy modelling with a parametric open L-system: a comparison with the Monsi and Saeki model, Field Crops Res. 58 (1998) 1-13.

[11] Drouet J.L., Moulia B., Spatial re-orientation of maize leaves affected by initial plant orientation and density, Agric. For. Meteorol. 88 (1997) 85-100.

[12] Dwyer L.M., Stewart D.W., Leaf area development in field-grown maize, Agron. J. 78 (1986) 334-343.

[13] Dwyer L.M., Stewart D.W., Effects of leaf age and position on net photosynthetic rates in maize (Zea mays L.), Agric. For. Meteorol. 37 (1986) 29-46.

[14] Dwyer L.M., Stewart D.W., Hamilton R.I., Houwing L., Ear position and vertical distribution of leaf area in corn, Agron. J. 84 (1992) 430-438. 
[15] Ephrath J.E., Hesketh J.D., Alm D.M., Leaf and stem characteristics in maize strains differing in stem leaf number, Photosynthetica 30 (1994) 381-388.

[16] España M.L., Simulation de la variation temporelle, directionnelle et spectrale de la reflectance de cultures de maïs à partir d'un modèle dynamique de la structure 3D du couvert, thèse, université de Marne-laVallée, France, 1997.

[17] España M.L., Baret F., Chelle M., Aries F., Andrieu B., A dynamic model of maize 3D architecture: application to the parameterisation of the clumpiness of the canopy, Agronomie 18 (1998) 609-626.

[18] España M.L., Baret F., Aries F., Andrieu B., Chelle M. Radiative transfer sensitivity to the accuracy of canopy structure description. The case of a maize canopy, Agronomie 19 (1999) 241-254.

[19] Fournier C., Introduction des réponses écophysiologiques à la température dans un modèle de plante à base de L-sytèmes, Mémoire de DEA, Institut national agronomique Paris-Grignon, 1995, 37p + annexes.

[20] Fournier C., Andrieu B., A 3D architectural and process-based model of maize development, Ann. Bot. 81 (1998) 233-250.

[21] Giauffret C., Bonhomme R., Dorvilez D., Derieux M., Conversion of intercepted radiation into aerial dry biomass for three maize genotypes: influence of plant density, Maydica 36 (1991) 25-27.

[22] Goel N.S., Knox L.B., Norman M.N., From artificial life to real life: computer simulation of plant growth, Int. J. Gen. Syst. 18 (1990) 291-319.

[23] Grant R.F., Simulation of maize phenology, Agron. J. 81 (1989) 451-457.

[24] Grant R.F., Hesketh J.D., Canopy structure of maize (Zea mays L.) at different populations: simulation and experimental verification, Biotronics 21 (1992) $11-24$.

[25] Grobbelaar W.P., Response of young maize plants to root temperatures, Meded. Landbouwhogesch. Wageningen 63 (1963) 1-71.

[26] Hanan J., Virtual plants-integrating architectural and physiological models, Environ. Model. Softw. 12 (1997) 35-42.

[27] Hanway J.J., Internode lengths at different developmental stages of corn (Zea mays L.), Agron. J. 62 (1970) 116-117.

[28] Jones C.A., Kiniry J.R., CERES-Maize, a simulation model of maize growth and development, T\&M University Press, College Station, USA 1986.
[29] Kaitaniemi P., Honkanen T., Simulating sourcesink control of carbon and nutrient translocation in a modular plant, Ecol. Model. 88 (1996) 227-240.

[30] Kasperbauer M.J., Karlen D.L., Plant spacing and reflected far-red light effects on phytochrome-regulated photosynthate allocation in corn seedlings, Crop Sci. 34 (1994) 1564-1569.

[31] Keating B.A., Wafula B.M., Modelling the fully expanded area of maize leaves, Field Crops Res. 29 (1992) 163-176.

[32] Kurth W., Sloboda B., Growth grammars simulating trees-an extension of L-systems incorporating local variables and sensitivity, Silva Fenn. 31 (1997) 285-295.

[33] Ledent J.F., Henkart T., Jacobs B., Phénologie du maïs, visualisation de la croissance et du développement, Rev. Agric. 43 (1990) 391-408.

[34] Maas S.J., Parametrized model of gramineous crop growth: I. Leaf area and dry mass simulation, Agron. J. 85 ( 1993) 348-353.

[35] Maas S.J., Parametrized model of gramineous crop growth: II. Within-season simulation calibration, Agron. J. 85 (1993) 354-358.

[36] Martin G.G., Cell growth in the maize stem, Ukr. bot. Zh. 45 (1988) 35-39 (in Russian, figures and summary in English).

[37] Mech R., Prusinkiewicz P., Visual models of plants interacting with their environment, Proceedings of SIGGRAPH '96, New Orleans, Louisiana, ACM SIGGRAPH, New York, 1996, pp. 397-410.

[38] Monteith J.L., Climate and the efficiency of crop production in Britain, Philos. Trans. R. Soc. Lond. Ser. B 281 (1977) 277-294.

[39] Morrison T.A., Kessler J.R., Buxton D.R., Maize internode elongation patterns, Crop Sci. 34 (1994) 1055-1060.

[40] Muchow R.C., Carberry P.S., Environmental control of phenology and leaf growth in a tropically adapted maize, Field Crops Res. 20 (1989) 221-236.

[41] Perthuis H., Modélisation du tallage du maïs par les L-systemes, Mémoire de DESS, université Paris V, U.F.R. de mathématiques et informatique, Paris, 1997.

[42] Perttunen R., Sievänen R., Nikinmaa E., Salminen H., Saarenmaa H., Väkevä J., LIGNUM: a tree model based on simple structural units, Ann. Bot. 77 (1996) 87-98.

[43] Plénet D., Fonctionnement des cultures de maïs sous contrainte azotée. Détermination et application d'un indice de nutrition, thèse de doctorat, Institut 
national polytechnique de Lorraine, Vandœuvre, France, 1995.

[44] Pommel B., Bonhomme R., Variations in the vegetative and reproductive systems in individual plants of an heterogeneous maize crop, Eur. J. Agron. 8 (1998) $39-49$.

[45] Pommel B., Fleury A., Etude de la variabilité individuelle chez le maïs à l'issue de la phase de d'implantation. Conséquences sur la croissance et la production de grain, Agronomie 9 (1989) 467-475.

[46] Popa G.S., Analyse des variations de structure aeriene de peuplements de maïs dans differentes conditions de competition intraspécifique, thèse, universite Paris XI, Orsay, France, 1997.

[47] Prévot L., Aries F., Monestiez P., Modélisation de la structure géométrique du maïs, Agronomie 11 (1991) 491-503.

[48] Prusinkiewicz P., A look at the visual modeling of plants using L-systems, Agronomie 19 (1999) 211-224.

[49] de Reffye P., Fourcaud T., Blaise F., Barthélémy D., Houllier F., A functional model of tree growth and tree architecture, Silva Fenn. 31 (1997) 297-311.

[50] Robertson M.J., Relationships between internode elongation, plant height and leaf appearance in maize, Field Crops Res. 38 (1994) 135-145.

[51] Salah H.B.H., Tardieu F., Quantitative analysis of the combined effects of temperature, evaporative demand and light on leaf elongation rate in well-watered field and laboratory-grown maize plants, J. Exp. Bot. 47 (1996) 1689-1698.

[52] Soontornchainaksaeng P., Mise en place de la surface foliaire, accumulation et répartition de la matière sèche chez le sorgho, thèse , Institut national polytechnique, Toulouse, France, 1995.

[53] Stirling C.M., Aguilera C., Baker N.R., Long S.P., Changes in the photosynthetic light response curve during leaf development of field grown maize with implications for modelling canopy photosynthesis, Photosynth. Res. 42 (1994) 217-225.
[54] Streit C., Graphtal user manual, SIG computer graphics, University of Berne, Switzerland, 1992.

[55] Tetio-Kagho F., Gardner F.P., Responses of maize to plant population density. 1. Canopy development, light relationships, and vegetative growth, Agron. J. 80 (1988) 930-935.

[56] Thiagarajah M.R., Hunt L.A., Effects of temperature on leaf growth in corn (Zea Mays), Can. J. Bot. 60 (1982) 1647-1652.

[57] Thiagarajah M.R., Hunt L.A., Mahon J.D., Effects of position and age on leaf photosynthesis in corn (Zea mays), Can. J. Bot. 59 (1981) 28-33.

[58] Thonat C., Analyse de la variabilité de la croissance foliaire de plantes de maïs bien irriguées et fertilisées, Mémoire de DESS, Université Blaise Pascal, Clermont-Ferrand, France, 1997, 42 p.

[59] Varlet-Granchet C., Bonhomme R., Chartier M., Artis P., Efficience de la conversion de l'énergie solaire par un couvert végétal, Oecol. Plant. 3 (1982) 3-26.

[60] Warrington I.J., Kanemasu E.T., Corn growth response to temperature and photoperiod. II Leaf-initiation and leaf-appearance rates, Agron. J. 75 (1983) 755-761.

[61] Watson M.A., Integrated physiological units in plants, Trends Ecol. Evol. 1 (1986) 119-123.

[62] Watson M.A., Casper B.R., Morphogenetic constraints on patterns of carbon distribution in plants., Annu. Rev. Ecol. Syst. 15 (1984) 233-258.

[63] Watts W.R., Leaf extension in Zea mays. II. Leaf extension in response to independent variation of the temperature of the apical meristem, of the air around the leaves, and of the root-zone, J. Exp. Bot. 23 (1972) 713-721.

[64] Williams W.A., Loomis R.S., Duncan W.G., Dovrat A., Nunez F.A., Canopy architecture at various population densities and the growth and grain yield of corn, Crop Sci. 8 (1968) 303-308.

[65] Zur B., Reid J.F., Hesketh J.D., The dynamics of maize canopy development, 1 . leaf ontogeny, Biotronics 18 (1989) 55-66. 